\title{
Resultados de uma Pesquisa de Opinião
}

Centro de Aperfeiçoamento, órgão autônomo vinculado ao DASP., promoveu, de 16 a 20 de outubro, um $2^{\circ}$ Ciclo de Conferências sôbre problemas da Administração Civil em face da evolução tecnológica e da liderança. Êsse $2^{\circ}$ Ciclo foi realizado em Brasília, no auditório do Ministério das Minas e Energia.

As conferências proferidas foram as seguintes:

1. Unificação da Previdência Social

Conferencista:

Francisco Luiz Torres de Oliveira

Presidente do Instituto Nacional da Previdência Social

2. A Política Educacional do Govêrno

Conferencista:

Tarso Dutra

Ministro da Educação e Cultura

3. Administração e Produtividade

Conferencista:

Eurico Rezende

Diretor da Faculdade de Administração de Emprêsas do Distrito Federal

4. Codebrás. Organização, Regulamentação, P 1 a n o de Transferência, Política de Mudança e Integração Nacional.

Conferencista:

Abel Raphael Pinto

Diretor Administrativo da Codebrás

5. Liderança e Chefia

Conferencista:

Wagner Estelita Campos

Ministro do Tribunal de Contas da União 
Ao terminar êsse Seminário, o Centro de Aperfeiçoamento submeteu o público a um questionário individual em que se pesquisava a opinião dos participantes sôbre diversos aspectos do Ciclo.

\section{O QUESTIONÁRIO}

1. Como tomou conhecimento do Ciclo de Conferências?

2. Que achou do Ciclo de Conferências?

3. Qual o tema ou temas de sua preferência?

4. Contribuição de cada palestra:

a) importância do assunto

b) exposição do assunto

5. Está convencido da necessidade de treinar os seus subordinados a melhor executarem suas tarefas?

6. Programação ( $\mathrm{N}^{\circ}$ de palestras, Periodo, Horário) .

7. Assuntos para um nôvo ciclo de conferências.

8. Que sugestões apresenta sôbre divulgação?

9. Local para realização de um nôvo ciclo de conferências.

\section{OS RESULTADOS OBTIDOS}

\section{Como tomou conhecimento do Ciclo de Conferências?}

$84 \%$ dos participantes tomaram conhecimento do Ciclo através do Centro de Aperfeiçoamento, seja de um modo direto, seja indiretamente, por intermédio de seus superiores imediatos; $8 \%$ souberam da realização do 2 . Ciclo de Conferências por acaso; apenas $2 \%$ tomaram conhecimento pela imprensa e $6 \%$ dêles não se pronunciaram.

Resumindo:

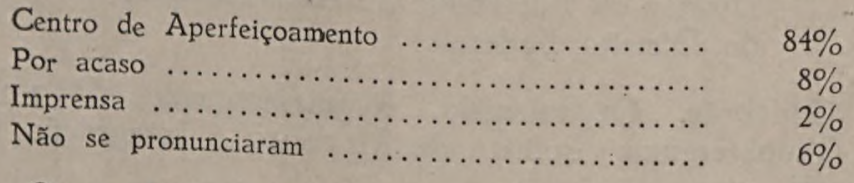

2. Que achou do Ciclo de Conferências?

Atribuindo ao 2: Ciclo de Conferências as classificações Sofrivel, Regular, Bom, Ótimo, obtivemos os seguintes resultados, por ordem decrescente:

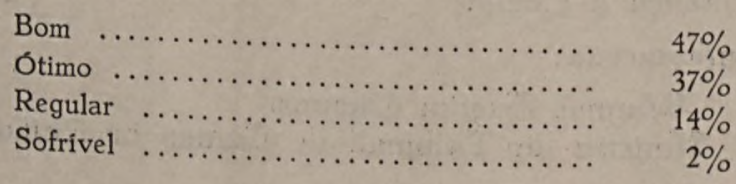



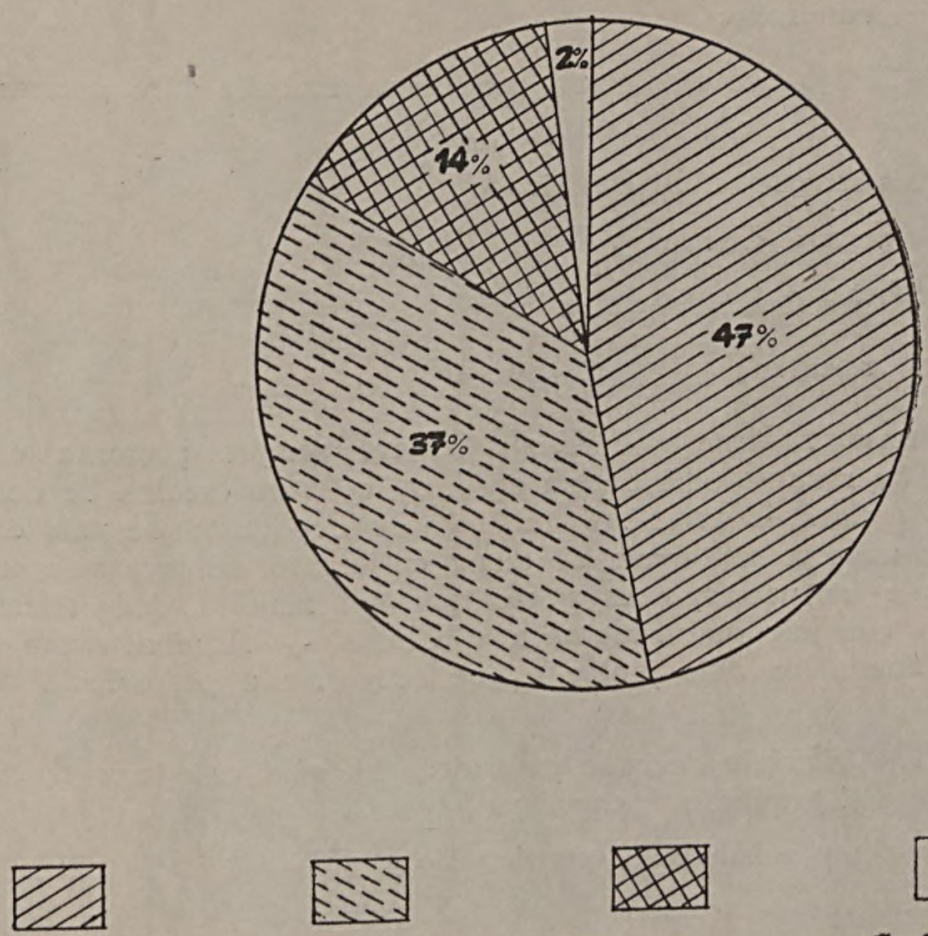

Bom

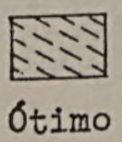

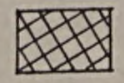

Regular

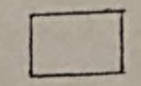

Sofrível

3. Qual o tema ou temas de sua preferência?

$1^{\circ}$ resultado:

$34,7 \%$ escolheram dois temas

$30,6 \%$ escolheram um só tema

$22,5 \%$ escolheram três temas

$6,1 \%$ escolheram quatro temas

$6,1 \%$ não se pronunciaram

$2^{\circ}$ resultado:

Tomando os que escolheram um só tema, isto é, os $30,6 \%$ do total, verificamos que, dêstes, $53,3 \%$ votaram no tema Liderança e Chefia; $20 \%$ em Política Educacional do Govêrno, 20\% em Administração e Produtividade e $6,7 \%$ em Codebrás.

\section{3. resultado:}

Dos $34,7 \%$ que escolheram dois temas, $41,1 \%$ preferiram Liderança e Chefia + Administração e Produtividade; $23,5 \%$ preferiram os temas Liderança e Chefia + Codebrás; as outras escolhas ficaram em tôrno de $11 \%$. 
4. resultado:

Dos $22,5 \%$ que escolheram três temas, mais de $40 \%$ votaram nos temas:

Administração e Produtividade

Liderança e Chefia

Codebrás

\section{5. resultado:}

O tema Liderança e Chefia estêve sempre presente em maioria, quer na escolha de um só tema, quer na escolha de dois ou mais temas. O tema Administração e Produtividade vem em 20 lugar na escolha de um só tema; entretanto, se levarmos em conta que os participantes preferiram em maioria dois temas, podemos concluir que Liderança e Chefia + Administração e Produtividade, os dois juntos é que retiveram a preferência do público.

4. Contribuição de cada palestra: 1) quanto à importância do assunto; 2) quanto à exposição.

Cotação prevista pelo questionário:

Excelente

Boa

Regular

Fraca

\section{COTAÇÃO dAS PALESTRAS EM ÍNDICES PERCENTUAIS}

1 - QUANTO À IMPORTÂNCIA DO ASSUNTO

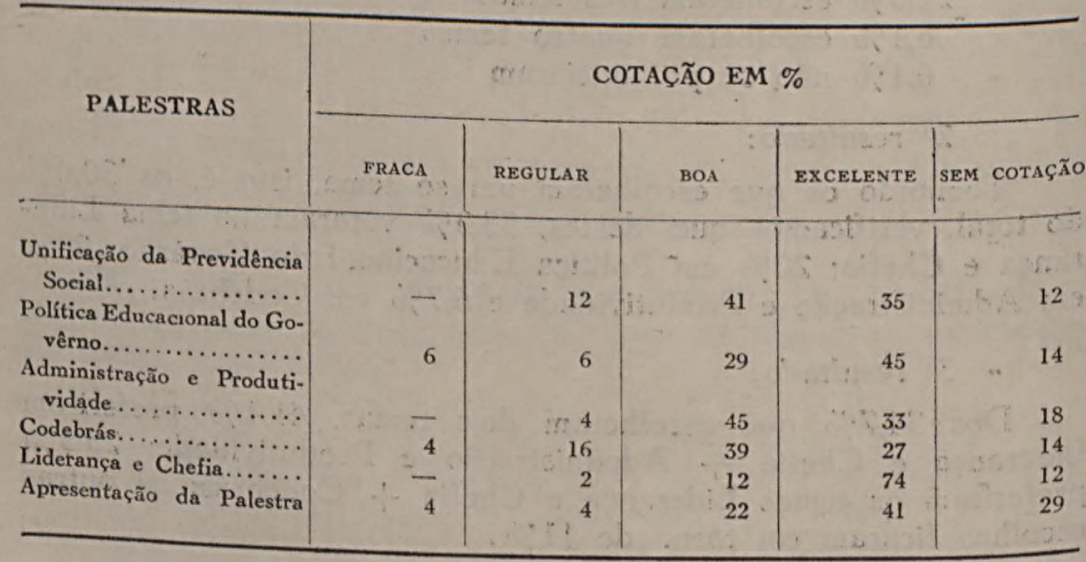




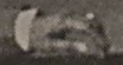

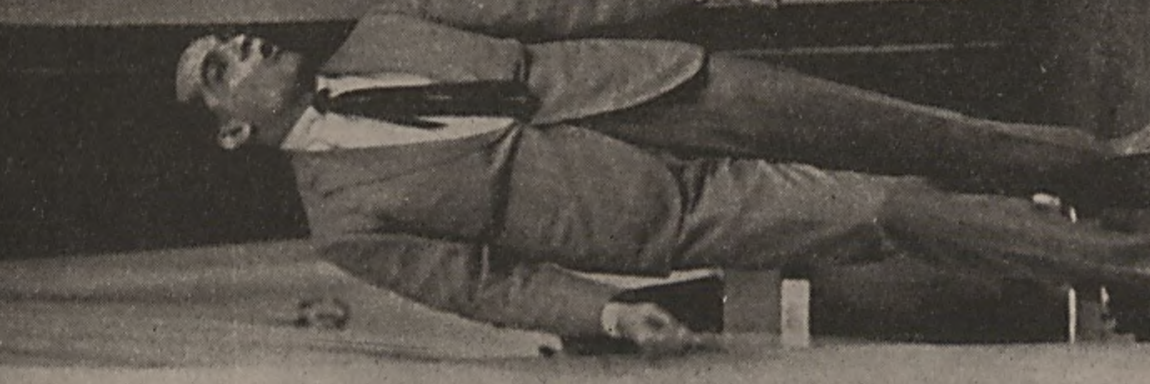

.
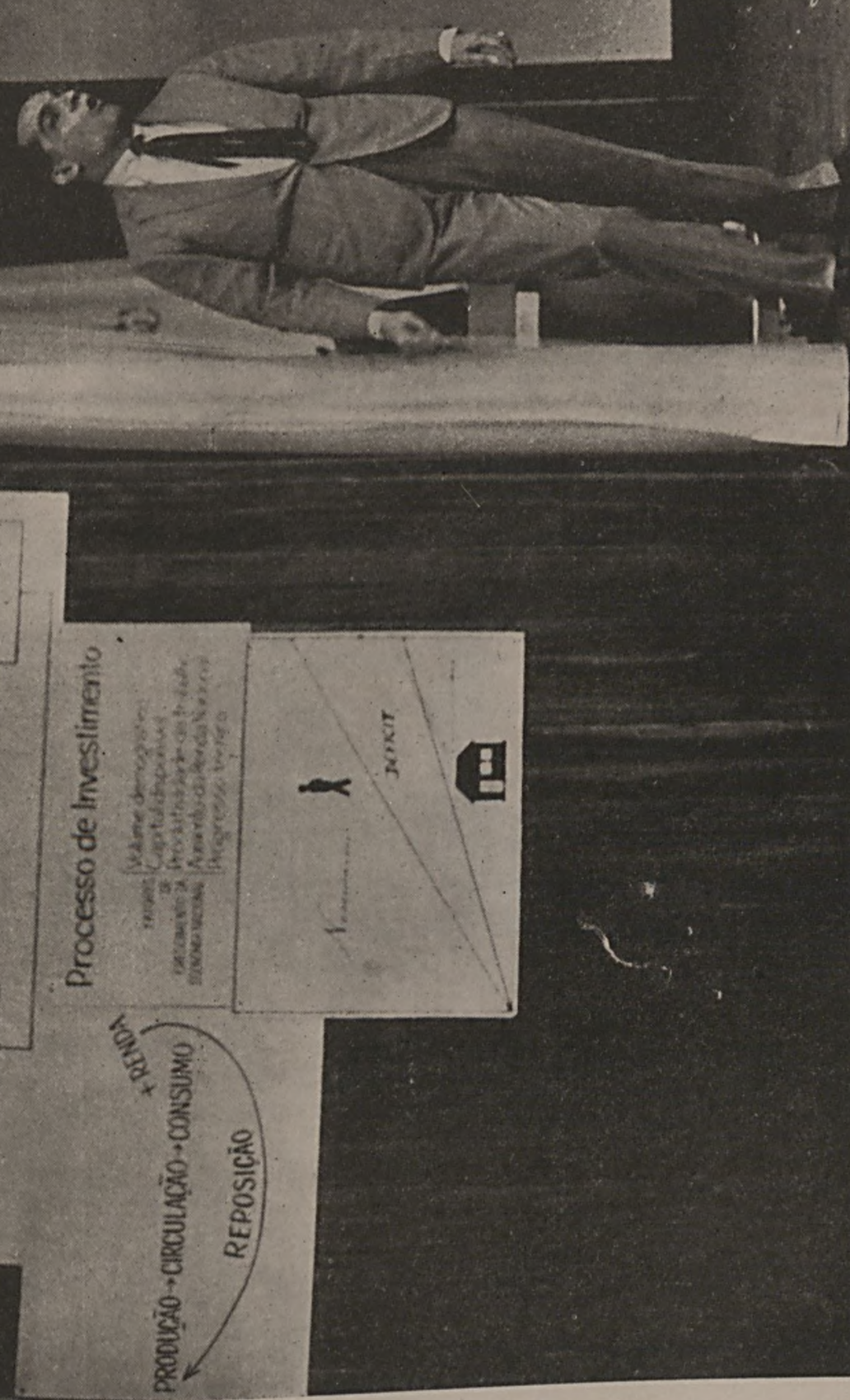

政

४ चี

ㄷำ

ปี

ปร ธิ

बै

워

芯芯

ज这

ธี ซี

ชูตั

ชิ

톤

हี $: 0$

ชูำ

ษัญ ฮี

पड

ชั:

온전

บัฐ

요 웅

- Eี

เั้

ลีฉ

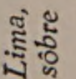

ชั ฐั

ปั

䒕㤎

2.

जU

से

జั.

ปั

ปั

ธัँ

0 


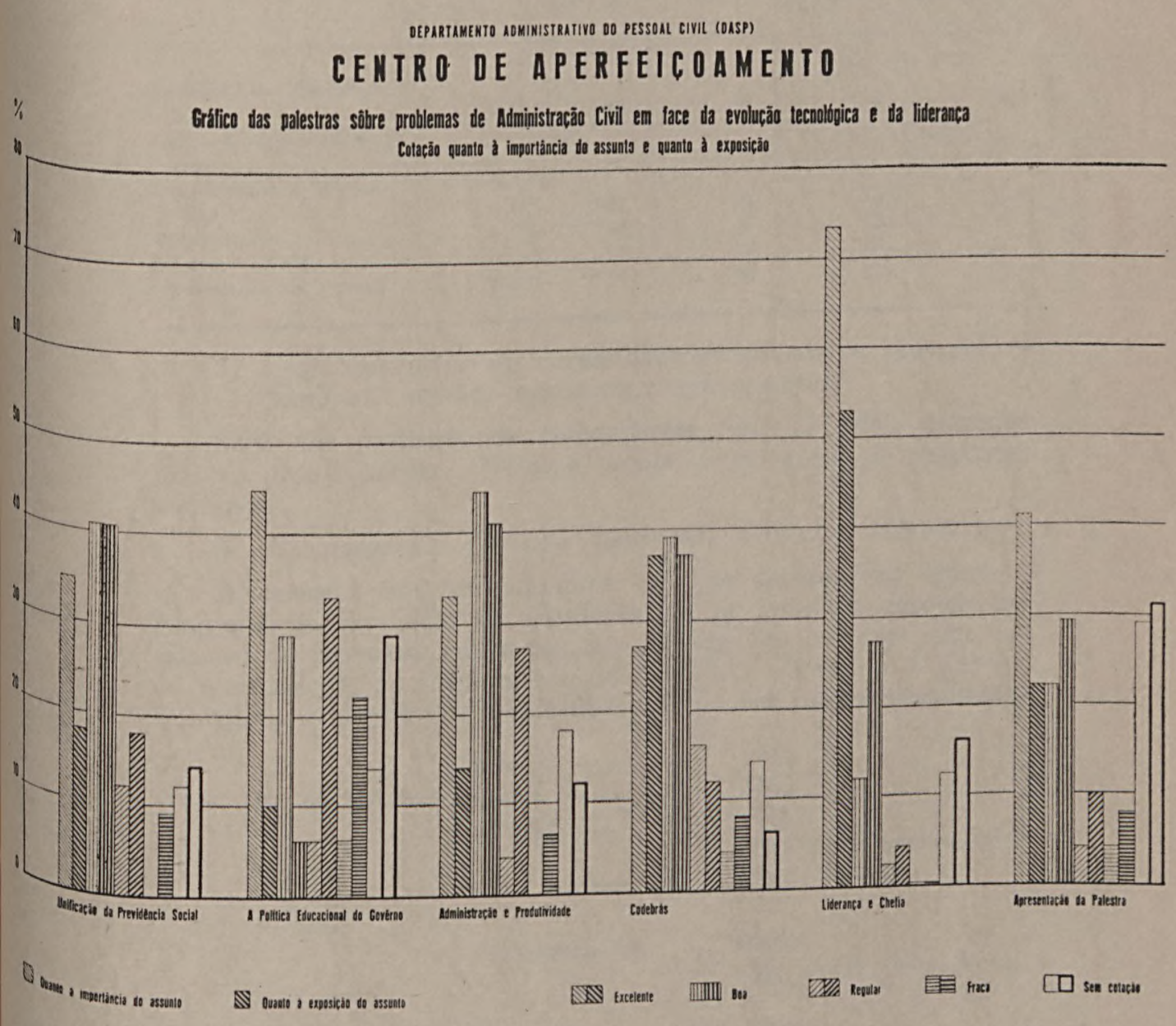




\section{2 - QUANTO À EXPOSIÇÃO DO ASSUNTO}

\begin{tabular}{|c|c|c|c|c|c|c|}
\hline \multirow{2}{*}{ PALESTRAS } & \multicolumn{6}{|c|}{ СОTAÇÃO EM \% } \\
\hline & FRACA & REGULAR & BOA & EXCELENTE & $\operatorname{sEM} C$ & Cotạ̧̃̃o \\
\hline $\begin{array}{r}\text { Unificação da Previdêncic } \\
\text { Social.................. }\end{array}$ & 9 & 18 & 41 & 18 & & 14 \\
\hline 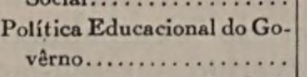 & 22 & 33 & 6 & 10 & & 29 \\
\hline $\begin{array}{r}\text { Administração e Produti- } \\
\text { vidade..................... }\end{array}$ & 6 & 27 & 41 & 14 & & 12 \\
\hline Codebrás................ & 8 & 12 & 37 & 37 & & 6 \\
\hline Liderança e Chefia....... & 一 & 4 & 27 & 53 & & 16 \\
\hline Apresentação da Palestra & 8 & 10 & 29 & 22 & & 31 \\
\hline
\end{tabular}

5. Está convencido da necessidade de treinar os seus subordinados a melhor executarem suas tarefas?

$82 \%$ dos participantes responderam Sim, os $18 \%$ restantes não se pronunciaram. Nota-se, assim, a ausência de respostas negativas.

6. Programação ( $N^{g}$ de palestras, Periodo, Horário).

A maioria dos participantes não se pronunciou sôbre a programação do Ciclo de Conferências no que diz respeito ao número de palestras realizadas, ao período ( $\mathrm{se} \mathrm{em}$ dias seguidos ou alternados), ao horário (se de manhã, à tarde ou à noite). Indicamos, a seguir, os resultados obtidos em proporcionalidade:

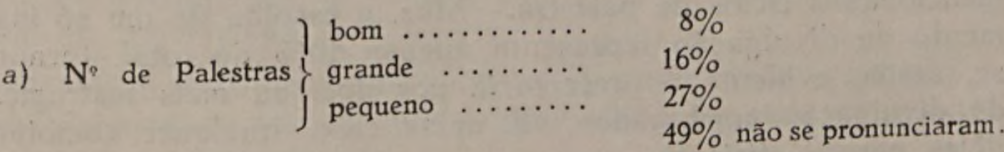
b) Periodo
$\begin{cases}\text { Dias seguidos ... } & 30,5 \% \\ \text { Dias alternados. } & 32.5 \%\end{cases}$
$37 \%$ não se pronunciaram.

$\left\{\begin{array}{l}\text { De manhã } \ldots \ldots \\ \text { A noite } \ldots \ldots \ldots \\ \text { A tarde } \ldots \ldots \ldots\end{array}\right.$
$4 \%$
$8 \%$
$41 \%$
$47 \%$ não se pronunciaram
c) Horário

7. Assuntos para um nôvo Ciclo de Conferências:

Arrolamos um total de 33 assuntos sugeridos para um próximo Ciclo de Conferências. Nesse total de 33 assuntos 
arrolados, verificamos que $50 \%$ dos participantes gostariam de que fôssem apresentados os seguintes temas num $2^{\circ}$ Ciclo de Conferências:

- Relações Humanas

- Relações Públicas

- Reforma Administrativa

- Liderança e Chefia

- Administração Pública

Ao sugerirem Liderança e Chefia, como assunto para um próximo Ciclo, $30 \%$ dos participantes assim se exprimiram: «ainda» Liderança e Chefia. O emprêgo do advérbio pareceu-me indicar não só um interêsse evidente pelo tema, como também uma necessidade dos participantes de que fôsse esgotado um assunto situado na faixa de maior interêsse do Centro de Aperfeiçoamento.

8. Que sugestões apresenta sôbre divulgação?

- Imprensa $\}_{\text {Jescrita }}^{\text {falada }}$

- Televisão

- Cartazes

Analisados os resultados pelas respostas obtidas, chegamos à seguinte conclusão:

A Imprensa escrita e a Televisão, cada um isoladamente, parecem ser os dois instrumentos que possibilitam, com maior eficiência, divulgar e ativar a penetração junto ao público dos mencionados ciclos de palestra. Mas, a escolha de um só instrumento de divulgação representa apenas $40 \%$ do total, tornandose, assim, evidente a preferência por dois ou mais instrumentos de divulgação combinados. $\mathrm{E}$ nesse caso, qualquer combinação dêles parece eficiente.

9. Local para realização de um nôvo Ciclo de Conferências.

- Ministério das Minas e Energia

- DASP

- Em qualquer local

Verificamos que $66 \%$ dos participantes não se pronunciaram sôbre a preferência do local para a realização de um futuro Ciclo de Conferências, 22\% optaram pelo Auditório do Ministério das Minas e Energia, $10 \%$ são indiferentes ao local escolhido e. apenas, $2 \%$ escolheram o DASP.

Somando-se os $66 \%$ que não se pronunciaram aos $10 \%$ de indiferentes, conclui-se que, para a grande maioria dos partici- 
pantes $(76 \%)$, a escolha do local não representa problema de importância.

\section{CONCLUSÕES}

Conjugados os fatôres coletados pela pesquisa de O.P. apresentada por ocasião do encerramento do II Ciclo de Conferências promovido pelo Centro de Aperfeiçoamento do DASP, observamos:

$\left.1^{\circ}\right)$ que a ação das R.P. direta atuou de maneira positiva como melhor veículo de difusão dos propósitos do Centro como podemos observar no quadro abaixo

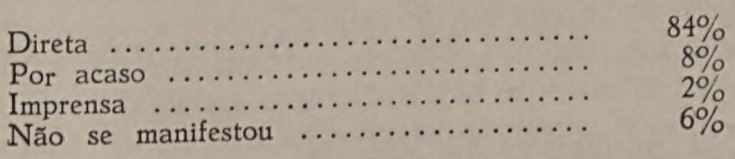

2\%) $84 \%$ dos participantes optaram pelo conceito bom e ótimo, de onde se conclui de que o ciclo foi altamente produtivo.

3?) Liderança e Chefia destacou-se sobremaneira como tema preferido, demonstrando mais uma vez a busca de auto-firmação do homem através de suas realizaçóes, devendo o tema figurar em futuras palestras como, aliás, poderá se confirmar mais adiante.

Seguiram-se Administração e Produtividade - Unificação da Previdência Social - Política Educacional do Govêrno e Codebrás, todos, também, largamente votados.

$4 \%$ ) $82 \%$ dos participantes pronunciaram-se favoráveis aos Cursos de Treinamento aos seus subordinados, objetivando melhor rendimento operacional.

$\left.5^{\circ}\right)$ Referente ao $\mathrm{n}^{\circ}$ de palestras, periodicidade e horário, o público demonstrou não ter ainda opinião bem formada, porquanto $44 \%$ não se manifestaram.

6:) Os temas sugeridos para futuras conferências foram os seguintes:

Relações Humanas

Relações Públicas

Reforma Administrativa

Liderança e Chefia

Administração Pública

7²) Não incluindo a divulgação direta, a mais positiva como constatamos, a Imprensa e Televisão figuraram como instrumentos preferidos de divulgação.

8.) Relativo ao local mostrou-se o auditório indiferente $(76 \%)$ quanto à localização. 